\title{
Article
}

\section{Design of a Wrist Rehabilitation System with a Novel Mixed Structural Optimization Applying Improved Harmony Search}

\author{
Eduardo Vega-Alvarado (D), Valentín Vázquez-Castillo, Edgar Alfredo Portilla-Flores *(D), \\ Maria Bárbara Calva-Yañez (D) and Gabriel Sepúlveda-Cervantes (D)
}

check for

updates

Citation: Vega-Alvarado, E.; Vázquez-Castillo, V;; Portilla-Flores, E.A.; Calva-Yañez, M.B.;

Sepúlveda-Cervantes, G. Design of a Wrist Rehabilitation System with a Novel Mixed Structural Optimization Applying Improved Harmony Search. Appl. Sci. 2021, 11, 1766. https:// doi.org/10.3390/app11041766

Academic Editor: José Machado Received: 31 December 2020 Accepted: 10 February 2021 Published: 17 February 2021

Publisher's Note: MDPI stays neutral with regard to jurisdictional clai$\mathrm{ms}$ in published maps and institutional affiliations.

Copyright: $(\odot 2021$ by the authors. Licensee MDPI, Basel, Switzerland. This article is an open access article distributed under the terms and conditions of the Creative Commons Attribution (CC BY) license (https:// creativecommons.org/licenses/by/ $4.0 /)$.
Instituto Politécnico Nacional-CIDETEC, Ciudad de México, Mexico City 07700, Mexico; evega@ipn.mx (E.V.-A.); vvazquezc0801@alumno.ipn.mx (V.V.-C.); calvayanezmb@gmail.com (M.B.C.-Y.); gsepulvedac@ipn.mx (G.S.-C.)

* Correspondence: aportilla@ipn.mx

\begin{abstract}
This paper presents the development of a wrist rehabilitation system with a novel approach for structural design, based on the modeling of an optimization problem solved by a metaheuristic algorithm, Improved Harmony Search (ImHS). It is part of a project for developing low-cost rehabilitation systems expressly designed for the population of Latin American countries. A mixed optimization problem is modeled for the design, where the material type is associated with an integer variable and the dimensions of the components are continuous parameters. The novelty is that each element is calculated individually, but considering the combined effect over the structure. The optimization works simultaneously on both the material selection and the meeting of the associated constraints, to guarantee that the system will not fail because of any load, neither it will be unsafe for the patients, since the operation will always be within the limits considered in the modeling. ImHS is a variant of the Harmony Search algorithm, modified to enhance the exploration and exploitation processes. It is a simple yet powerful metaheuristic, implemented in this development with additional modifications to handle constraints and mixed variables. The proposed approach produced quality results, indicating that ImHS can be applied to solve complex engineering problems, facilitating the manufacture and control processes.
\end{abstract}

Keywords: harmony search; optimization; engineering hard problems; wrist rehabilitation

\section{Introduction}

Cerebral strokes are the main cause of neurological impairments worldwide [1], with a survival rate of $60-75 \%$. About $80-90 \%$ of the survivors suffer from a reduction or complete loss of their psycho-motor functions [2]. Other factors such as accidents or different diseases also affect these functions. The mobility effect negatively impacts life quality and Daily Living Activities (DLA) such as eating, grooming or dressing. There is a great necessity of rehabilitation for these patients but most classical methods are difficult to implement, because they demand a high physical effort from the therapist [3]. Robotic systems are a good option since they support the high intensity, steady performance and long activity periods required [4]. The wrist is one of the most exposed joints to trauma, injuries or strokes, and diverse devices have been developed for its rehabilitation. An exoskeleton with elastic actuators was developed in [5]. In [6], a rehabilitation system with force sensing was built. A structure for the 3-DOF movements of the wrist by either arm was presented in [7]. In [8], a training glove with pneumatic actuators is designed, and in [9] a 3-DOF exoskeleton is presented.

However, none of the aforementioned works includes the detailed design of the structural component. Most developments are focused on the system control, and generally the devices are over-dimensioned and difficult to produce. The development of computing tools has accelerated the design process, simplifying the manufacture and control while ensuring a safer operation. Few works consider these aspects, highlighting the development 
of Gandomi et al. [10], with a structural design carried out by metaheuristics, one element at a time. Several methodologies have been proposed, such as Concurrent Design (CD) [11], Design For Control (DFC) [12], Design For A (A = life cycle, manufacture, etc.) [13], and Multidisciplinary Design Optimization (MDO) [14]. Most structural optimization cases have both non-linear objective functions and constraints, with limited search spaces, making it impossible to solve the associated optimization problems by classic techniques, so metaheuristics are a useful tool for their solution. Many works have addressed aspects as the weight optimization to maximize stiffness $[15,16]$, or the topology optimization of beams for different stress types $[17,18]$.

Harmony Search (HS) is a metaheuristic developed by Geem et al. [19] on the basis that a harmony is a certain sound combination and the search for the best harmony is analogous to finding a solution for an optimization problem [20]. It presents a good balance between exploration and exploitation, an easy and low-cost computational implementation with few mathematical requirements, and fast convergence [21]. It has been applied in fields such as engineering [22-26], computing [27,28], image processing [29,30], and electronics [31]. In relation to the scope of this work, HS has been successfully used in different medical applications. In [32], it is applied to select the adequate features for a digital hearing aid device, after classifying the acoustic environment where the user is immerse. A method called MRMR-COA-HS is proposed in [33] for a two-stage gene selection, with a hybrid combination of the Cuckoo Optimization Algorithm (COA) and HS for cancer classification. In [34], HS is used with the entropy of Kapur in a method for image segmentation by thresholding, to detect skin cancer in early stages. Another segmentation technique based on HS is presented in [35], for analyzing magnetic resonance images (MRI). In [36], the authors developed an application for medical physics, using HS to optimize the radioisotope placement of a high dose-rate brachytherapy for prostate cancer. There are also diverse works on HS-based structural design. In [37,38], the efficiency of HS for solving this type of problems is analyzed, and a tool based on HS for the design of a three-span box-girder bridge is presented in [39].

In this work, the structural design of a wrist rehabilitation system is modeled as an optimization problem focused on the weight of the device [40], presenting an approach that simultaneously considers the manufacturing material selection and the meet of the constraints associated to the rehabilitation system. The novelty is that each element is calculated individually, but considering the combined effect over the structure. This paper is organized as follows: Section 2 presents the modeling of the rehabilitation system, describing its functionality and the component analysis while Section 3 explains the optimization method. Section 4 describes the optimization problem and the solution algorithm. The results are given in Section 5 and the final discussion in Section 6.

\section{Problem Statement}

The best strategy during the design process of mechanical systems is to identify their components [41] and revise them separately, but including the combined effect of all the elements to avoid structural failures. The von-Mises theory is useful for stress analysis when a combined axial-bending-shear load acts on a structural component. The criterion of Goodman is employed to analyze elements in a structure dynamically loaded under combined stress, performing the fatigue analysis by any of the currently accepted failure theories $[42,43]$. According to the distortion energy theory, the maximum strain is given by Equation (1), where $\sigma_{f}, \sigma_{a}$, and $\tau_{s}$ are the stress generated by bending, axial load, and shear, respectively; and $k_{f}=1, k_{a}=0.85$, and $k_{t}=0.59$ are the stress concentration factors for bending, axial load, and shear, respectively, as recommended in [42].

$$
\sigma^{\prime}=\left[\left(k_{f} \sigma_{f}+k_{a} \frac{\sigma_{a}}{0.85}\right)^{2}+3\left(k_{s} \tau_{s}\right)^{2}\right]^{\frac{1}{2}}
$$




\subsection{Case Study}

The wrist joint performs its movements along two axes, each corresponding to a DOF: Flexion/Extension (FL/EX) and Radial Deviation (RD)/Ulnar Deviation (UD). It is oriented by a third DOF, the Pronation (P)/Supination (S) movement of the elbow joint. Figure 1a shows the rehabilitation device proposed by Aponte-Rodriguez et al. [40] to reproduce these 3-DOF. It is part of a join project between the Instituto Politecnico Nacional (Mexico) and the Universidad Militar Nueva Granada (Colombia), to develop low-cost rehabilitation systems expressly designed for the population of Latin American countries. The specifications of the device components were determined from the motion ranges proposed in [1,44] and the hand anthropometry for the Latin American population [45]. The torques required to drive each articulation were considered for the structural analysis, taking into account both the requirements of the DLA and the values proposed in literature $[1,3,46]$. The RD/UD and FL/EX movements are actuated directly by servomotors connected to the structural components. For this reason, an adequate design is critical for a safe operation.

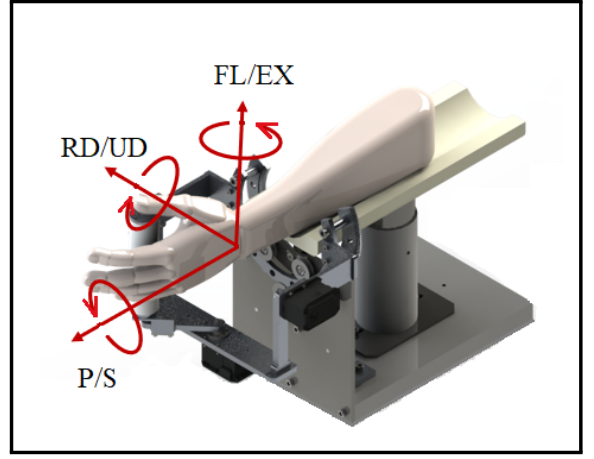

(a) Basic system.

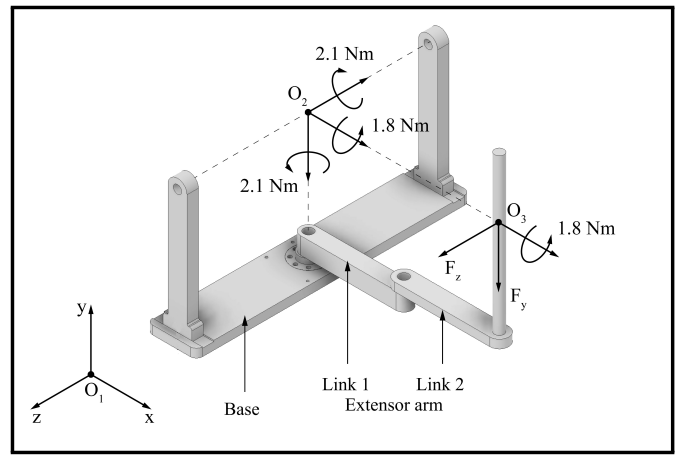

(b) Proposed modification.

Figure 1. Wrist rehabilitation mechanism.

The development in this paper (Figure $1 b$ ) is a continuation of the aforementioned project, and consists in a modification to the extensor arm of the mechanism with two links instead of one to facilitate the wrist movements. The size of each link is determined by its length $l$, width $W$, thickness $t$, and diameter $d$ (Figure 2a), and both of them form an open kinematic chain. The links should be as light as possible, to take advantage of the highest torque in the hand movement during the therapy. The solution method tackles the simultaneous design of more than one structural element, considering the interaction and joint effect while designing. Although this work only analyzes two links, all the mobile elements are designed with the same methodology. A complex mixed-optimization problem is obtained, with both the objective function and the constraints of non-linear type. The free-body diagrams (Figure 2b) consider the bending and torsional external loads for the combined stress. The bending stress is calculated for each link by Equation (2), with Equations (3) and (4) for the bending moments and the second moments of area, respectively. The torque is $T_{x y}=3.571 \mathrm{Nm}$, and the forces are $F_{z 1}=F_{z 2}=25.3 \mathrm{~N}$, and $F_{y 1}=F_{y 2}+$ weight of link 2, and $F_{y 2}=30.4 \mathrm{~N}+E F$ [40], with an extra load $E F=49 \mathrm{~N}$ for this case. The shear stress produced by torsion is calculated by Equation (5), with $W>t$.

$$
\begin{gathered}
\sigma_{f}=\frac{M_{y}}{I_{y y}}+\frac{M_{z}}{I_{z z}} \\
M_{y}=\frac{l \times W \times F_{y}}{2}, \quad M_{z}=\frac{l \times t \times F_{z}}{2} \\
I_{y y}=\left(\frac{1}{12} t\right)\left(W^{3}-d^{3}\right), \quad I_{z z}=\left(\frac{1}{12} W-d\right)\left(t^{3}\right)
\end{gathered}
$$




$$
\tau_{s}=\frac{3 T_{x y}}{8 a b^{2}}\left(1+0.6095\left(\frac{t}{W}\right)+0.88665\left(\frac{t}{W}\right)^{3}+0.91\left(\frac{t}{W}\right)^{4}\right)
$$

There is no load generating an axial force, so $\sigma_{a}=0$. The maximum total deflection is obtained using Equations (6) and (7), where $E$ is the elastic modulus of the selected material:

$$
\begin{array}{r}
\delta_{\max }=\sqrt{\left(y_{x y}\right)^{2}+\left(y_{x z}\right)^{2}} \\
y_{x y}=\frac{F_{y} l^{3}}{3 E I_{y y}}, \quad y_{x z}=\frac{F_{z} l^{3}}{3 E I_{z z}}
\end{array}
$$

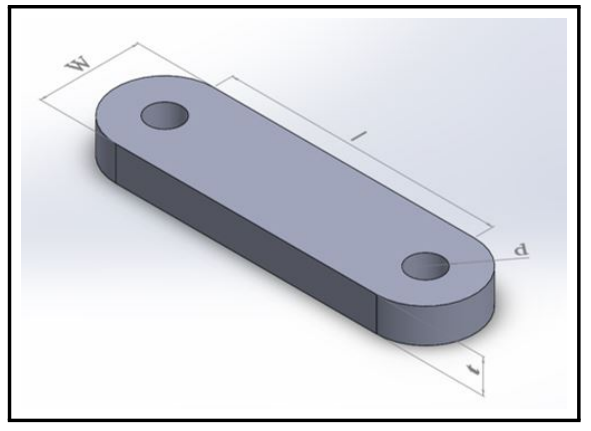

(a) Design parameters.

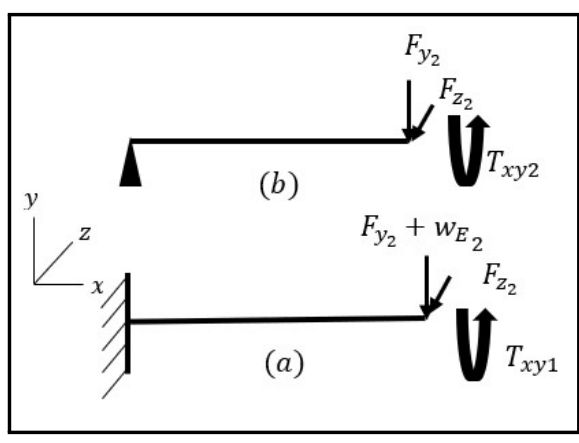

(b) Free-body diagram (a) link 1, (b) link 2.

Figure 2. Specification of links.

\section{Optimization Problem}

In this work, Improved Harmony Search is used to solve a structural design case, tackling simultaneously the dimensional synthesis and the material selection of more than one element at a time, considering both the interaction and joint effect of the components. A mathematical problem for weight optimization is proposed to obtain the dimensions and material required for each element, meeting the design constraints. This is a mixed problem, because the material selection is a discrete variable, while the dimensions are continuous. The procedure is as follows: given a set of materials, a load state, the maximum allowable deflections and the minimum safety factor allowed, it is desired to find the width, thickness, and appropriate material to build each link.

\subsection{Objective Function}

It is required to optimize the weight of the links to implicitly optimize the power consumption and the costs associated to the structure. The objective function in Equation (9) corresponds to the total weight, including a sum term for each link, where $l$ and $d$ are the link length and diameter, respectively, and $g$ is the gravitational acceleration. Expression (9) presents the design vector, where $x_{1}, x_{2}$, and $x_{3}$ are the material type, thickness, and width of link 1 , respectively, while $x_{4}, x_{5}$, and $x_{6}$ are the same parameters for link 2 .

$$
\begin{array}{r}
\min f(\vec{x})=x_{1} g x_{2}\left(l x_{3}+\frac{\pi}{4} x_{3}^{2}-\frac{\pi}{2} d^{2}\right)+x_{4} g x_{5}\left(l x_{6}+\frac{\pi}{4} x_{6}^{2}-\frac{\pi}{2} d^{2}\right) \\
\vec{x}=\left[x_{1}, x_{2}, x_{3}, x_{4}, x_{5}, x_{6}\right]^{T}=\left[\rho_{1}, t_{1}, W_{1}, \rho_{2}, t_{2}, W_{2}\right]^{T}
\end{array}
$$

The material type is a discrete variable that must guarantee the device will not fail due to loading. This discards materials without a defined fatigue limit, such as polymerics, ceramics or compounds. There are studies establishing the endurance limits for metal alloys [42,47]. Alloys in Table 1 were selected because they met the design requirements, are used in medical non invasive applications, and are commercially available. They can be changed in type and/or number to meet specific design requirements. 
Table 1. Physical properties of the selected materials.

\begin{tabular}{ccccc}
\hline Type & Material & $\begin{array}{c}\text { Density } \boldsymbol{\rho} \\
{\left[\mathbf{k g} / \mathbf{m}^{3}\right]}\end{array}$ & $\begin{array}{c}\text { Elastic Modulus } E \\
{[\mathrm{~Pa}]}\end{array}$ & $\begin{array}{c}\text { Endurance Limit } \boldsymbol{S}_{\boldsymbol{e}} \\
{[\mathrm{Pa}]}\end{array}$ \\
\hline 1 & Aluminum 7075 T6 & 2810 & $71.7 \times 10^{9}$ & $121 \times 10^{9}$ \\
\hline 2 & Steel AISI 1045 CD & 7870 & $205 \times 10^{9}$ & $236 \times 10^{9}$ \\
\hline 3 & Steel AISI 304L & 8000 & $195.4 \times 10^{9}$ & $240 \times 10^{9}$ \\
\hline
\end{tabular}

\subsection{Limits and Constraints}

The desired values of the security factor and maximum deflection are $n_{d}=2$ and $\delta_{d}=5 \times 10^{-4} \mathrm{~m}$, respectively, and the ranges of the design variables are defined in expressions (10)-(12). Dimensions $d=8 \times 10^{-3} \mathrm{~m}$ and $l=8.3 \times 10^{-2} \mathrm{~m}$ are previously set, but can be included as design variables to be calculated if required.

$$
\begin{array}{r}
x_{1}, x_{4}=\{2810,7870,8000\} \\
\frac{d}{2} \leq x_{2}, x_{5} \leq 6 d \\
1.25 d \leq x_{3}, x_{6} \leq 3.3 d
\end{array}
$$

Equality expressions (13) guarantee a specific stiffness of the links, while inequality expressions (14) guarantee a minimum security factor for each link. Constraints in inequality expressions (15) are derived from the condition $W>t$ in Equation (5):

$$
\begin{array}{rrr}
h_{1}=\delta_{\max 1}-\delta_{d}=0, & h_{2}=\delta_{\max 2}-\delta_{d}=0 \\
g_{1}=n_{d}-\frac{S e_{1}}{\sigma_{1}^{\prime}} \leq 0, & g_{2}=n_{d}-\frac{S e_{2}}{\sigma_{2}^{\prime}} \leq 0 \\
g_{3}=\left(1.1 * t_{1}\right)-W_{1} \leq 0, & g_{4}=\left(1.1 * t_{2}\right)-W_{2} \leq 0
\end{array}
$$

\subsection{Problem Complexity}

The relation between the feasible zone and the total search space of an optimization problem can be used to express its complexity [48]. This parameter, represented by $C_{\rho}$ and calculated by Equation (16), corresponds to the percentage of feasible vectors $F$ in an arbitrary large number of random solutions $S$. As can be seen, a very low value of $C_{\rho}$ corresponds to an extremely high complexity, that requires a higher computing effort. One million randomly generated solutions [49] were used to calculate this complexity for the selected problem, and no feasible vectors were found between them, producing $C_{\rho}=0$. The computational characteristics of the design problem are shown in Table 2:

$$
C_{\rho}=\frac{F}{S} \times 100 \%
$$

Table 2. Computational characteristics of the case study.

\begin{tabular}{cccc}
\hline $\begin{array}{c}\text { Design } \\
\text { Variables }\end{array}$ & $\begin{array}{c}\text { Equality } \\
\text { Constraints }\end{array}$ & $\begin{array}{c}\text { Inequality } \\
\text { Constraints }\end{array}$ & $\begin{array}{c}\text { Complexity } \\
\mathrm{C}_{\rho}\end{array}$ \\
\hline 6 & 2 & 4 & 0 \\
\hline
\end{tabular}

\section{Optimization Method}

The first options to consider when solving numerical optimization problems are mathematical programming techniques. Most of those methods require both the objective function and the constraints to be doubly and continuously differentiable with respect to each decision variable. Nevertheless, in many problems, the accomplishment of these 
conditions cannot be guaranteed, and alternative solution methods are required. Metaheuristics are approximate stochastic methods that have proved to be quite efficient for solving complex engineering design problems, such as the presented in this work.

\subsection{Improved Harmony Search}

Diverse versions of HS have been developed to improve its stability and the quality of the generated solutions. ImHS [50] is a variant that includes two modifications to enhance the performance of HS without affecting its simplicity. The first one is the change of the parameter bandwidth $b w$, reducing it at each algorithm iteration to improve the exploitation process. Further, $b w$ is personalized for each design variable considering the individual value ranges. The second modification is the inclusion of an additional parameter, the rate of improvement adjustment $r_{i a}$, to give more variety to the process of combining different options to create new solutions, improving the exploration.

\subsection{Computational Implementation}

Most metaheuristics were developed to solve unconstrained problems. Different schemes have been implemented for constraint handling (a complete description can be found in [51]). In this sense, the feasibility rules of Deb [52] are very popular because of its simplicity and high efficiency. In this work, they are combined with ImHS by applying a Constraint Violation Sum (CVS) for comparison-then-selection of solutions. CVS is an accumulator for the absolute excess value of each unmet constraint, to directly measure the feasibility grade of a solution. The rules in ImHS work as follows:

- Between two infeasible harmonies, pick the one with the lowest CVS.

- Between a feasible and an infeasible harmonies, select the feasible one.

- Between two feasible harmonies, take the one with the best objective-function value.

ImHS was also modified for processing mixed variables, with a round operation [53] that transforms a real number into the nearest integer to generate the index corresponding to a specific material. Algorithm 1 corresponds to the pseudo-code of the implemented ImHS. It can easily be tuned by trial and error, in this case with $H M=16$ harmonies, Iterations $=5000$ iterations, $R_{a c c e p t}=0.85$, and $R_{p a}=0.45, r_{i a}=0.66$. However, diverse strategies for a better tuning can be applied, as explained in [54,55].

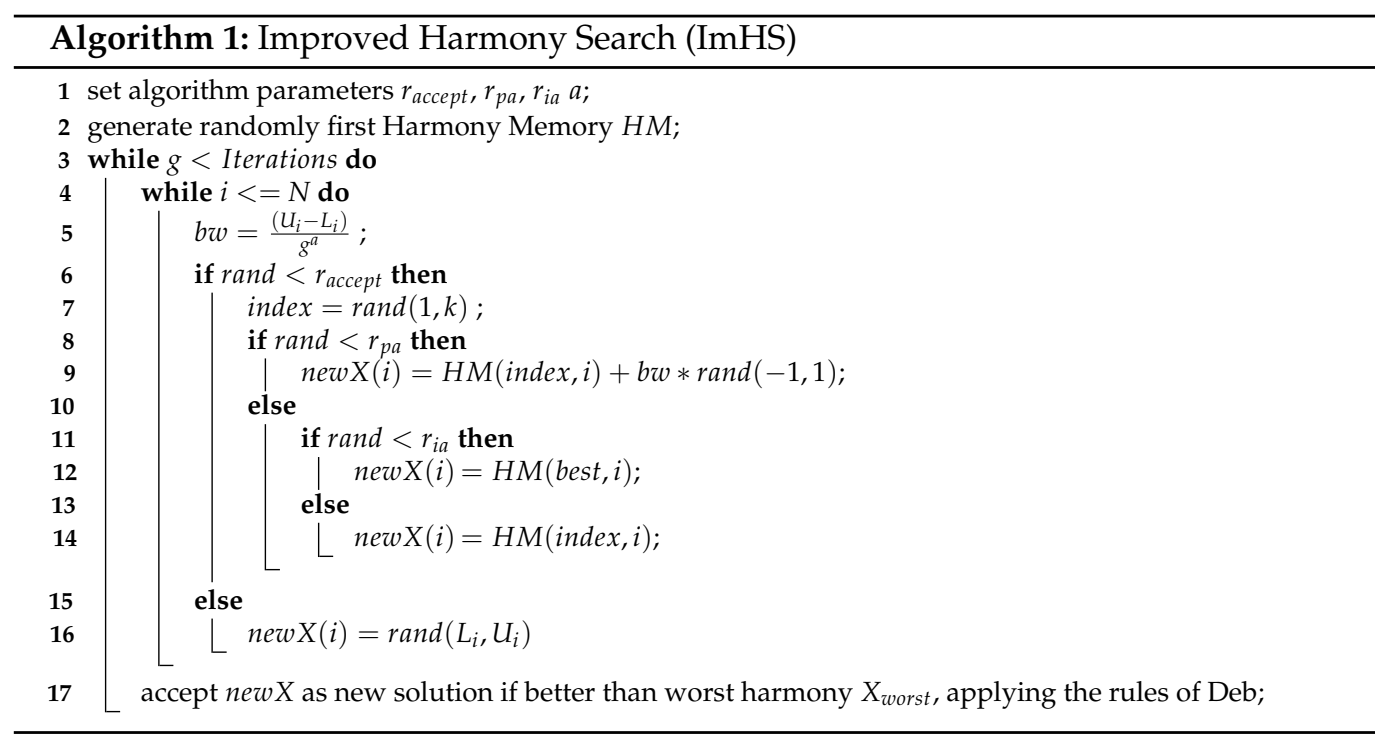

\section{Results}

ImHS had a 100\% feasible rate in the solution of the case study, since each of their simulations produced one or more feasible solutions. In Table 3, the first five best solutions are presented, while Table 4 includes a statistical analysis of the performance. There is a 
similarity between the average value and the median, indicating a homogeneous distribution of the results. In addition, the dispersion of the result set in relation to the arithmetic mean, given by the variance, shows a steady operation of the algorithm. For comparison purposes, the case study was also solved with Differential Evolution (DE) [56], a popular and efficient metaheuristic for solving constrained numerical optimization problems. DE rand $/ 1 /$ bin was selected for this case because of its simple implementation. Table 5 shows the best solution obtained by each algorithm. As can be seen, the solution from ImHS surpassed the best value of DE requiring a considerable lower amount of resources, 30,000 vs. 500,000 evaluations of the objective function.

Table 3. First five best solutions of ImHS.

\begin{tabular}{|c|c|c|c|c|c|c|c|}
\hline \multirow[b]{2}{*}{ Rank } & \multicolumn{3}{|c|}{ Link 1} & \multicolumn{3}{|c|}{ Link 2} & \multirow[b]{2}{*}{$\begin{array}{c}\text { Total } \\
\text { Weight (N) }\end{array}$} \\
\hline & Type & $\begin{array}{c}\text { Thickness } \\
\text { (m) }\end{array}$ & $\begin{array}{l}\text { Width } \\
\text { (m) }\end{array}$ & Type & $\begin{array}{c}\text { Thickness } \\
\text { (m) }\end{array}$ & $\begin{array}{l}\text { Width } \\
\text { (m) }\end{array}$ & \\
\hline 1 & 1 & 0.00725 & 0.02409 & 1 & 0.00672 & 0.01772 & 0.77042 \\
\hline 2 & 1 & 0.00720 & 0.02444 & 1 & 0.00780 & 0.01585 & 0.77990 \\
\hline 3 & 1 & 0.00615 & 0.02382 & 1 & 0.00686 & 0.02149 & 0.78011 \\
\hline 4 & 1 & 0.00866 & 0.01990 & 1 & 0.01021 & 0.01383 & 0.78143 \\
\hline 5 & 1 & 0.00951 & 0.01806 & 1 & 0.00563 & 0.02514 & 0.81949 \\
\hline
\end{tabular}

Table 4. Statistics of the performance of ImHS for the case study.

\begin{tabular}{cccccc}
\hline Best & Worst & Average & Median & Variance & Std Dev \\
\hline 0.77042 & 1.07628 & 0.86923 & 0.87400 & 0.00745 & 0.08631 \\
\hline
\end{tabular}

Table 5. Best solutions of ImHS and ED/rand/1/bin.

\begin{tabular}{cccccccccc}
\hline & \multicolumn{3}{c}{ Link 1 } & & & \multicolumn{3}{c}{ Link 2 } & \\
\cline { 2 - 3 } Algorithm & Type & $\begin{array}{c}\text { Thickness } \\
(\mathbf{m})\end{array}$ & $\begin{array}{c}\text { Width } \\
(\mathbf{m})\end{array}$ & & Type & $\begin{array}{c}\text { Thickness } \\
(\mathbf{m})\end{array}$ & $\begin{array}{c}\text { Width } \\
(\mathbf{m})\end{array}$ & $\begin{array}{c}\text { Total } \\
\text { Weight (N) }\end{array}$ \\
\hline ImHS & 1 & 0.00725 & 0.02409 & & 1 & 0.00672 & 0.01772 & 0.77042 \\
DE & 1 & 0.01097 & 0.01593 & & 1 & 0.01099 & 0.01590 & 0.86021 \\
\hline
\end{tabular}

The best result of ImHS was tested with the Finite Element Method (FEM) using ANSYS Workbench 2015, to verify if it met the problem constraints and boundaries. The simulation includes all the operation loads and stress sources considered in the design (Figure 3). The red end of each link shows the maximum deflection. These deflections were in the order of $1.18 \times 10^{-4} \mathrm{~m}$, lower than the established maximum limit of $5 \times 10^{-4} \mathrm{~m}$, validating that the links will operate within the operational ranges without failure. 


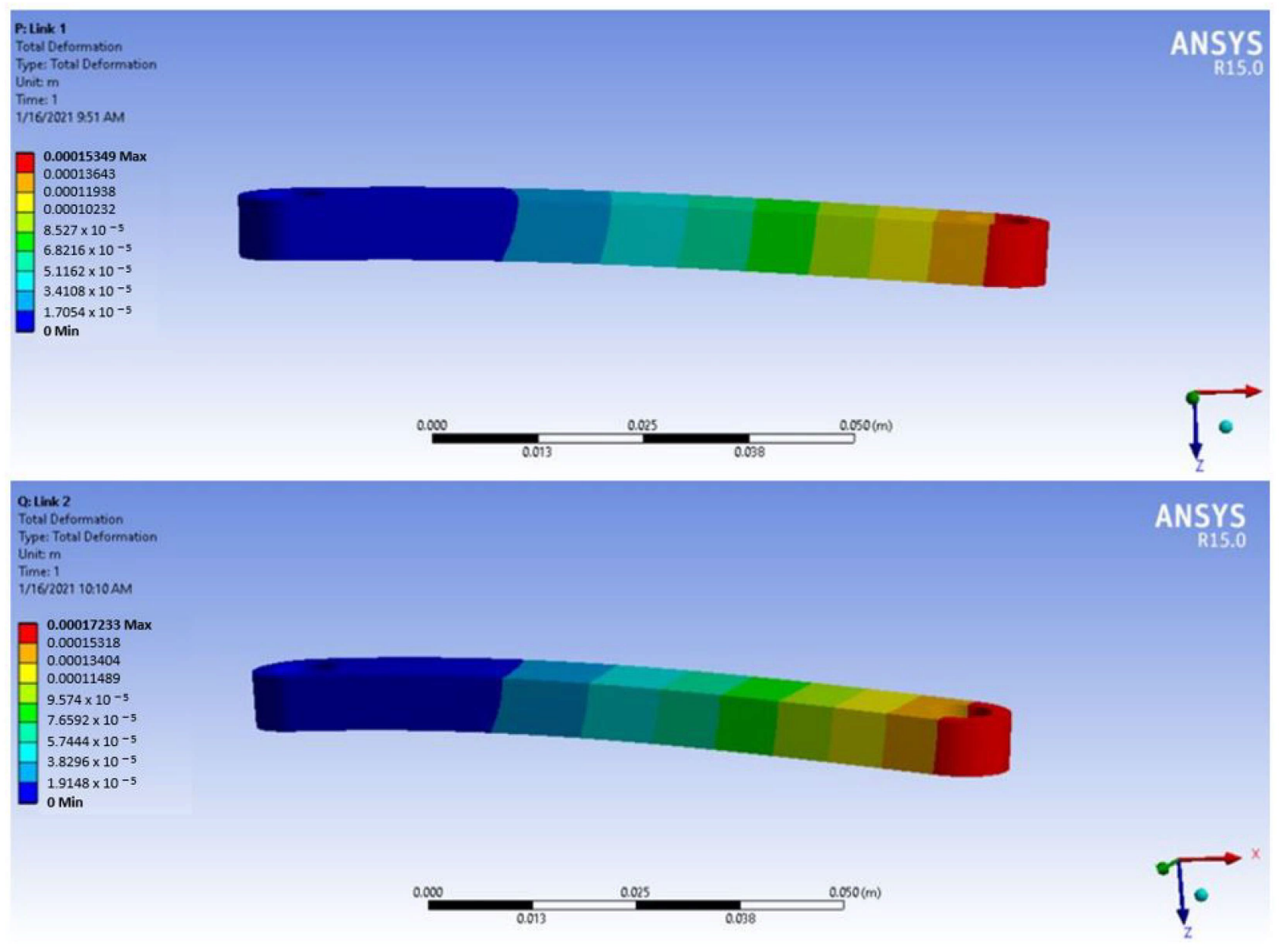

Figure 3. FEM analysis of both links using ANSYS Workbench 2015.

\section{Discussion}

In this paper, the structural design of a wrist rehabilitation system is carried out by a concurrent methodology, with a novel approach where the optimization process works simultaneously on both the material selection and the constraint meeting. A metaheuristic is applied to the dimensional synthesis and the material selection of more than one structural element at a time, considering the interaction and joint effect while designing. The modeling of the system as an optimization problem adds flexibility to its solution. Once it is modeled, the problem can be adapted to configuration changes. There is no limitation on the materials to be chosen, and the geometries to be analyzed can be as complex as is required by the design, demonstrating the versatility of the method.

The associated optimization problem is a complex one solved with the Improved Harmony Search algorithm, modified for handling constraints and mixed variables. It generates design alternatives that can be evaluated from different perspectives such as cost, ease of manufacture and assembly. The results show that the performance of ImHS is stable and with a low computational cost, making it a good option to solve real-life problems if they are modeled as constrained cases. The quality of the design results guarantees that the physical implementation of the rehabilitation system will be safe for the patients, since they met the safety constraints established in the problem modeling.

As future work, we consider the manufacturing of a prototype of the wrist rehabilitation device designed with the proposed method, in order to test it with real users. For the prototype, it is necessary to develop a control system, but the considerations for the concurrent design will simplify that task. Finally, we suggest considering to implement a strategy for dynamic parameter tuning to improve the performance of ImHS. 
Author Contributions: Conceptualization and methodology, V.V.-C. and E.A.P.-F.; validation and formal analysis, M.B.C.-Y. and G.S.-C.; investigation and software, E.V.-A. All authors have read and agreed to the published version of the manuscript.

Funding: This research received no external funding.

Institutional Review Board Statement: Not applicable.

Informed Consent Statement: Not applicable.

Data Availability Statement: Data is contained within the article.

Acknowledgments: The authors wish to thank Instituto Politécnico Nacional of México, for its support via Secretaría de Investigación y Posgrado with the SIP projects 20201934 and 20201944.

Conflicts of Interest: The authors declare no conflict of interest. The funders had no role in the development of the study or in the decision to publish the results.

\section{References}

1. Marini, F.; Hughes, C.M.L.; Squeri, V.; Doglio, L.; Moretti, P.; Morasso, P.; Masia, L. Robotic wrist training after stroke: Adaptive modulation of assistance in pediatric rehabilitation. J. Robot. Auton. Syst. 2017, 91, 169-178. [CrossRef]

2. Benjamin, E.J.; Blaha, M.J.; Chiuve, S.E.; Cushman, M.; Das, S.R.; Deo, R.; De Ferranti, S.D.; Floyd, J.; Fornage, M.; Gillespie, C.; et al. Heart disease and stroke statistics-2017 update: A report from the American Heart Association. J. Circ. 2017, 135, e146-e603. [CrossRef]

3. Omarkulov, N.; Telegenov, K.; Zeinullin, M.; Tursynbek, I.; Shintemirov, A. Preliminary mechanical design of nu-wrist: A 3-DOF self-aligning wrist rehabilitation robot. In Proceedings of the 2016 6th IEEE International Conference on Biomedical Robotics and Biomechatronics (BioRob), Singapore, 26-29 June 2016; pp. 962-967.

4. Bütefisch, C.; Hummelsheim, H.; Denzler, P.; Mauritz, K. Repetitive training of isolated movements improves the outcome of motor rehabilitation of the centrally paretic hand. J. Neurol. Sci. 1995, 130, 59-68. [CrossRef]

5. Sergi, F.; Lee, M.M.; M; Malley, K.O. Design of a series elastic actuator for a compliant parallel wrist rehabilitation robot. In Proceedings of the 2013 IEEE 13th International Conference on Rehabilitation Robotics (ICORR), Seattle, WA, USA, 24-26 June 2013; pp. 1-6.

6. Kim, H.M.; Hong, T.K.; Kim, G.S. Design of a wrist rotation rehabilitation robot. In Proceedings of the The 4th Annual IEEE International Conference on Cyber Technology in Automation, Control and Intelligent, Hong Kong, China, 4-7 June 2014; pp. 240-245.

7. Sajadi, M.R.; Nasr, A.; Moosavian, S.A.A.; Zohoor, H. Mechanical design, fabrication, kinematics and dynamics modeling, multiple impedance control of a wrist rehabilitation robot. In Proceedings of the 2015 3rd RSI International Conference on Robotics and Mechatronics (ICRoM), Tehran, Iran, 7-9 October 2015; pp. 290-295.

8. Al-Fahaam, H.; Davis, S.; Nefti-Mezian, S. Wrist rehabilitation exoskeleton robot based on pneumatic soft actuators. In Proceedings of the 2016 International Conference for Students on Applied Engineering (ICSAE), Newcastle upon Tyne, UK, 20-21 October 2016; pp. 491-496.

9. Pezent, E.; Rose, C.G.; Deshpande, A.D.; O’Malley, M.K. Design and characterization of the OpenWrist: A robotic wrist exoskeleton for coordinated hand-wrist rehabilitation. In Proceedings of the 2017 International Conference on Rehabilitation Robotics (ICORR), London, UK, 17-20 July 2017; pp. 720-725.

10. Gandomi, A.H.; Yang, X.-S.; Alavi, A.H. Mixed variable structural optimization using firefly algorithm. Comput. Struct. 2011, 6, 2325-2336. [CrossRef]

11. Li, Q.; Zhang, W.J.; Chen, L. Design for control—A concurrent engineering approach for mechatronic systems design. IEEE/ASME Trans. Mechatronics 2001, 6, 161-169. [CrossRef]

12. Bordoloi, S.; Guerrero, H.H. Design for control-A new perspective on process and product innovation. Int. J. Prod. Econ. 2008, 113, 346-358. [CrossRef]

13. Kuo, T.C.; Huang, S.H.; Zhang, H.C. Design for manufacture and design for x: Concepts, applications, and perspectives. Comput. Ind. Eng. 2001, 41, 241-260. [CrossRef]

14. Yao, X.; Moon, S.K.; Bi, G. Multidisciplinary design optimization to identify additive manufacturing resources in customized product development. J. Comput. Des. Eng. 2017, 4, 131-142. [CrossRef]

15. Sharafi, P.; Teh, L.H.; Hadi, M.N. Shape optimization of thin-walled steel sections using graph theory and ACO algorithm. J. Constr. Steel Res. 2014, 101, 331-341. [CrossRef]

16. Shimoda, M.; Liu, Y.; Ishikawa, K. Optimum shape design of thin-walled cross sections using a parameter-free optimization method. Thin-Walled Struct. 2020, 148. [CrossRef]

17. Manevich, A.I.; Raksha, S.V. Two-criteria optimization of h-section bars-beams under bending and compression. Thin-Walled Struct. 2007, 45, 898-901. [CrossRef]

18. Ozbasaran, H.; Yilmaz, T. Shape optimization of tapered i-beams with lateral-torsional buckling, defletion and stress constraints. J. Constr. Steel Res. 2018, 143, 119-130. [CrossRef] 
19. Geem, Z.; Kim, J.; Loganathan, G. A New Heuristic Optimization Algorithm: Harmony Search. Simulation: Trans. Soc. Model. Simul. Int. 2001, 76, 60-68. [CrossRef]

20. Yang, X. Harmony Search as a Metaheuristic Algorithm. In Music-Inspired Harmony Search Algorithm: Theory and Applications; Geem, Z.W., Ed.; Springer: Berlin, Germany, 2009; Volume 191, pp. 1-14. ISBN 978-3-642-00185-7.

21. Mahdavi, M.; Fesanghary, M.; Damangir, E. An Improved Harmony Search Algorithm for Solving Optimization Problems. Appl. Math. Comput. 2007, 188, 1567-1579. [CrossRef]

22. Degertekin, S.O. Improved Harmony Search Algorithms for Sizing Optimization of Truss Structures. Comput. Struct. 2012, 92-93, 229-241. [CrossRef]

23. Maheri, M.R.; Narimani, M.M. An Enhanced Harmony Search Algorithm for Optimum Design of Side Sway Steel Frames. Comput. Struct. 2014, 136, 78-89. [CrossRef]

24. Geem, Z.W.; Cho, Y. Optimal Design of Water Distribution Networks Using Parameter-Setting-Free Harmony Search for Two Major Parameters. J. Water Resour. Plan. Manag. 2010, 137. [CrossRef]

25. Yousefi, M.; Enayatifar, R.; Darus, A.N.; Abdullah, A.H. Optimization of Plate-fin Heat Exchangers by an Improved Harmony Search Algorithm. Appl. Therm. Eng. 2013, 50, 877-885. [CrossRef]

26. Manjarres, D.; Landa-Torres, I.; Gil-Lopez, S.; Ser, J.D.; Bilbao, M.N.; Salcedo-Sanz, S.; Geem, Z.W. A survey on applications of the harmony search algorithm. Eng. Appl. Artif. Intell. 2013, 26, 1818-1831. [CrossRef]

27. Assad, A.; Deep, K. Applications of Harmony Search Algorithm in Data Mining: A Survey. In Proceedings of Fifth International Conference on Soft Computing for Problem Solving, Saharanpur, India, 18-20 December 2015; pp. 863-874.

28. Tseng, S. An improved harmony search for traveling salesman problem. In Proceedings of the 2016 2nd IEEE International Conference on Computer and Communications (ICCC), Chengdu, China, 14-17 October, 2016; pp. $299-302$.

29. Cuevas, E. Block-matching algorithm based on harmony search optimization for motion estimation. Appl. Intell. 2013, 39, 165-183. [CrossRef]

30. Saparudin, F.A.; Kurniawan, A. Harmony Search Algorithm with Dynamic Pitch Adjustment Rate and Fret Width for Image Compression. In Proceedings of the Asia Pacific Conference on Multimedia and Broadcasting (APMediaCast), Bali, Indonesia, 17-19 November 2016.

31. Mallick, S.; Sudhakar, K.; Kar, R.; Mandal, D.; Ghoshal, S.P. CMOS Analog Amplifier Circuit sizing using Opposition based Harmony Search Algorithm. In Proceedings of the 2016 International Conference on Communication and Signal Processing (ICCSP), Melmaruvathur, Tamilnadu, India, 6-8 April 2016.

32. Alexandre, E.; Alvarez, L.; Amor, J.; Gil-Pita, R.; Huerta, E. Music-Inspired Harmony Search Algorithm Applied to Feature Selection for Sound Classification in Hearing Aids. In Proceedings of the AES 124th Convention Proceedings, 17-20 May 2008, Amsterdam, The NetherlandsAmsterdam, The Netherlands; Volume 2.

33. Elyasigomari, V.; Lee, D.A.; Screen, H.R.; Shaheed, M.H. Development of a two-stage gene selection method that incorporates a novel hybrid approach using the cuckoo optimization algorithm and harmony search for cancer classification. J. Biomed. Inform. 2017, 67, 11-20. [CrossRef]

34. Vinoth, N.; Vijayakarthick, M.; Ram, A.G.; Meyyappan, S.; Sathishbabu, S. Thresholding of Skin Melanoma Images based on Kapur's Entropy with Harmony Search Algorithm. Eur. J. Mol. Clin. Med. 2020, 7, 716-726.

35. Alia, O.M.; Mandava, R.; Ramachandram, D.; Aziz, M.E. Harmony search-based cluster initialization for fuzzy c-means segmentation of MR images. In Proceedings of the TENCON 2009-2009 IEEE Region 10 Conference, Singapore, 23-26 January 2009; pp. 1-6.

36. Panchal, A. Harmony Search in Therapeutic Medical Physics. InMusic-Inspired Harmony Search Algorithm: Theory and Applications; Springer: Berlin/Heidelberg, Germany, 2009; pp. 189-203. ISBN 978-3-642-00185-7.

37. Saka, M.; Hasançebi, O.; Geem, Z.W. Metaheuristics in Structural Optimization and Discussions on Harmony Search Algorithm. Swarm Evol. Comput. 2016, 28. [CrossRef]

38. Srikanth, D.; Barai, S.V. Structural Optimization Using Harmony Search Algorithm. In Soft Computing in Industrial Applications. Advances in Intelligent and Soft Computing; Gao, X.Z., Gaspar-Cunha, A., Köppen, M., Schaefer, G., Wang, J., Eds.; Springer: Berlin/Heidelberg, Germany, 2010; Volume 75.

39. García-Segura, T.; Yepes, V.; Alcalá, J. Computer-support tool to optimize bridges automatically. Int. J. Comput. Methods Exp. Meas. 2017, 5, 171-178. [CrossRef]

40. Aponte-Rodríguez, J.A.; Portilla-Flores, E.A.; Avilés-Sánchez, O.F.; Prada-Jiménez, V.; Vega-Alvarado, E. Concurrent design applied to the structural optimization of a wrist rehabilitation system. In Proceedings of the 14th International Conference on Electrical Engineering, Mexico City, Mexico, 20-22 September 2017; pp. 1-6.

41. Rao, R.V.; Savsani, V.J.; Vakharia, D.P. Teaching-learning-based optimization: A novel method for constrained mechanical design optimization problems. Comput. Aided Des. 2011, 43, 303-315. [CrossRef]

42. Budynas, R.G.; Nisbett, K. Shigley's Mechanical Engineering Design, 10th ed.; McGraw Hill Education: New York, NY, USA, 2015.

43. Mott, R.; Vavrek, E.; Wang, J. Machine Elements in Mechanical Design, 6th ed.; Pearson Education: New York, NY, USA, 2017.

44. Kapandji, A.; Lacomba, M., Fisiología articular: Esquemas comentados de mecánica humana; Editorial Médica Panamericana: Ciudad de México, Mexico, 2006, Volume 1. ISBN:9788498354584

45. Avila, R.; Prado, L.; González, E. Dimensiones antropométricas de la población latinoamericana: México, Cuba, Colombia, Chile; Universidad de Guadalajara: Guadalajara, Mexico, 2007. 
46. French, J.A.; Rose, C.G.; Malley, M.K.O. System characterization of mahi exo-ii: A robotic exosqueleton for upper extremity rehabilitation. In Proceedings of the ASME 2014 Dynamic Systems and Control Conference, San Antonio, TX, USA, 22-24 October 2014.

47. Lampman, S.; Boring, R.; Committee, A.I.H.; Davidson, G.; Hammel, A.; Henry, S.; Reidenbach, F.; Scott, W. ASM Handbook: Fatigue and Fracture; ASM International: Novelty, OH, USA, 1996.

48. Liang, J.; Runarsson, T.; Mezura-Montes, E.; Suganthan, P.; Clerc, M.; Coello, C.; Deb, K. Problem Definitions and Evaluation Criteria for the CEC 2006 Special Session on Constrained Real-Parameter Optimization; Technical Report; Nanyang Technological University: Singapore, 2006.

49. Michalewicz, Z.; Schoenauer, M. Evolutionary algorithms for constrained parameter optimization problems. Evol. Comput. 1996, 4, 1-32. [CrossRef]

50. Portilla-Flores, E.A.; Sánchez-Márquez, A.; Flores-Pulido, L.; Vega-Alvarado, E.; Yañez, M.B.C.; Aponte-Rodríguez, J.A.; NiñoSuarez, P.A. Enhancing the Harmony Search Algorithm Performance on Constrained Numerical Optimization. IEEE Access 2017, 5. [CrossRef]

51. He, X.S.; Fan, Q.W.; Karamanoglu, M.; Yang, X.S. Comparison of Constraint-Handling Techniques for Metaheuristic Optimization. In Computational Science - ICCS 2019, Lecture Notes in Computer Science; Rodrigues, J.M.F., Cardoso, P.J.S., Monteiro, J., Lam, R., Krzhizhanovskaya, V.V., Lees, M.H., Dongarra, J.J., Sloot, P.M.A., Eds.; Springer: Cham, Switzerland, 2019 ; Volume 11538.

52. Deb, K. An efficient constraint handling method for genetic algorithms. Comput. Methods Appl. Mech. Eng. 2000, 186, 311-338. [CrossRef]

53. AHammoudi; Djeddou, F. Composite differential evolution algorithm: mixed variable structural optimization problem. J. Chem. 2015, 3, 3-8.

54. Gao, S.; Zhou, M.; Wang, Y.; Cheng, J.; Yachi, H.; Wang, J. Dendritic Neuron Model With Effective Learning Algorithms for Classification, Approximation, and Prediction. IEEE Trans. Neural Netw. Learn. Syst. 2019, 30, 601-614. [CrossRef]

55. Wang, J.; Kumbasar, T. Parameter optimization of interval Type-2 fuzzy neural networks based on PSO and BBBC methods. IEEE/CAA J. Autom. Sin. 2019 6, 247-257. [CrossRef]

56. Storn, R.; Price, K. Differential evolution, a simple and efficient heuristic for global optimization over continuous spaces. J. Glob. Optim. 1997, 11, 341-359. [CrossRef] 